\title{
Protective factors of marital stability in long-term marriage globally: a systematic review
}

\author{
Reza Karimi, Maryam Bakhtiyari, Abbas Masjedi Arani \\ Department of Clinical Psychology, School of Medicine, Shahid Beheshti University of Medical Sciences, Tehran, Iran
}

\begin{abstract}
OBJECTIVES: In recent decades, due to the high prevalence of divorce in numerous countries and the detrimental aftermath thereof, it has become increasingly important to study the components of marital stability. The current study explored fundamental protective factors in long-term marriage through a systematic review.

METHODS: Searches for relevant publications were conducted in Embase, Web of Science, PubMed, Scopus, Science Direct, Magiran, and Scientific Information Database from their inception through January 30, 2019. Through the keyword search, 1,706 articles were found, of which 25 articles remained after screening based on the eligibility criteria.
\end{abstract}

RESULTS: The extracted protective factors associated with marital stability in long-term marriage were classified as interpersonal and intrapersonal. Notable extracted factors included spirituality and religion, commitment, sexual relationship, communication, children, love and attachment, intimacy, and conflict resolution approach. These findings show that some aspects of relationships, such as commitment, act to preserve the pillars of marriage in critical situations, while other aspects, such as intimacy, help to construct marital identity and satisfaction.

CONCLUSIONS: The identified components of marital stability are structures that enhance a couple's identity and sense of togetherness. Identifying the specific aspects of marital relationships that contribute to marital stability may help specialists and researchers to target specific types of marital interaction that may enhance the happiness and longevity of relationships, thereby preventing avoidable divorces.

KEY WORDS: Long-term marriage, Protective factors, Marital stability, Divorce, Systematic review

\section{INTRODUCTION}

In the present era, personal and intimate relationships have been established to have positive effects on physical and psychological health in older adults, and most of our perceptions about these linkages come from findings based on long-term marriage [1]. In the past century, although many couples have chosen to

\section{Correspondence: Maryam Bakhtiyari}

Department of Clinical Psychology, School of Medicine, Shahid Beheshti University of Medical Sciences, Arabi Street, Tehran 1985711151, Iran

E-mail:maryam_bakhtiyari@sbmu.ac.ir

Received: Jun 4, 2019 / Accepted: Jun 15, 2019 / Published: Jun 15, 2019

This article is available from: http://e-epih.org/

(c) This is an open-access article distributed under the terms of the Creative Commons Attribution License (http://creativecommons.org/licenses/by/4.0/), which permits unrestricted use, distribution, and reproduction in any medium, provided the original work is properly cited.

(C) 2019, Korean Society of Epidemiology stay together in long-term marriages for at least 40 years [2], divorce and separation rates have steadily increased and divorce has become a feasible choice for most couples [3]. Notwithstanding, most existing research in the literature on marriage has focused on the early [4] and middle years of marriages [5], whereas the literature on long-term marriages is sparse [6].

Researchers have investigated a wide factors related to longterm marriage, including attitudes towards marital relations [7]; religion [8-10]; the role of children [2]; love, commitment, and intimacy [11]; gender [12]; communication and conflict resolution [13]; support [14]; attachment and loyalty [15]; and role division [16].

Both older and more recent studies have suggested that the negative components of marital relationships tend to be more closely associated with marital longevity than do the positive components of the physical and psychological well-being of couples [17-21], while many other studies have reported that positive aspects of relationships protect marital stability $[2,7,11]$. Further- 
more, still other research has suggested that combinations of negative and positive factors in a relationship contribute to couples staying together in long-lasting marriages [22,23].

Furthermore, in previous studies, inconsistent findings have been reported regarding gender differences in the protective factors affecting marital success. Some studies have found considerable resemblances in what men and women consider exigent to marital success [24] whereas other studies have found more differences than similarities $[25,26]$.

Inconsistent findings have been reported in the literature regarding whether negative or positive aspects of marital relationships are associated with marital length, and inconsistencies exist with regard to gender differences in these issues. Additionally, in previous studies, the protective factors involved in long-term marriage have been reported to include a broad range of components. Considering these gaps, the purpose of the current study was to shed light on the diverse trajectories of the ingredients of long-term marriages and to explore the important elements that protect marital stability among couples in long-term marriages through a review of all relevant qualitative and quantitative studies.

\section{MATERIALS AND METHODS}

\section{Search strategy}

We undertook a systematic search in Persian and English electronic databases. The first step in the strategy entailed a limited search of publications in MEDLINE (MeSH) and Embase (Emtree) to identify key search terms. The key terms focused on marriage length and were combined using the "OR" operator (long-term marriage OR lasting marriage OR stable marriage OR sustainable marriage OR enduring marriage). The second step of the search involved the use of key search terms in a comprehensive database search without time limitation, from the inception of each database to January 30, 2019. Two reviewers independently searched the following 7 electronic databases: PubMed, Embase, Scopus, Science Direct, Web of Science, Magiran, and Scientific Information Database (SID). Two of those databases-SID and Magiran - are Persian databases. The initial literature search retrieved the following numbers of articles: MEDLINE (309), Scopus (733), Science Direct (112), Web of Science (492), Embase (56), Magiran (5), and SID (3). Overall, 1,706 articles were retrieved from the database searches, of which a total of 25 articles remained after the review process shown in Figure 1.

The inclusion criteria for articles were as follows: the participants were heterosexual couples (husbands or wives), the condition of interest was long-term marriage, the focus was on some aspect of the motivators of long-term marriage or marital satisfaction as a proxy of long-term marriage, the title and abstract of the article were written in English, and the article text was written in English or Persian.

\section{Data extraction}

Two independent investigators extracted all major components using a pre-established structured checklist. The extracted data
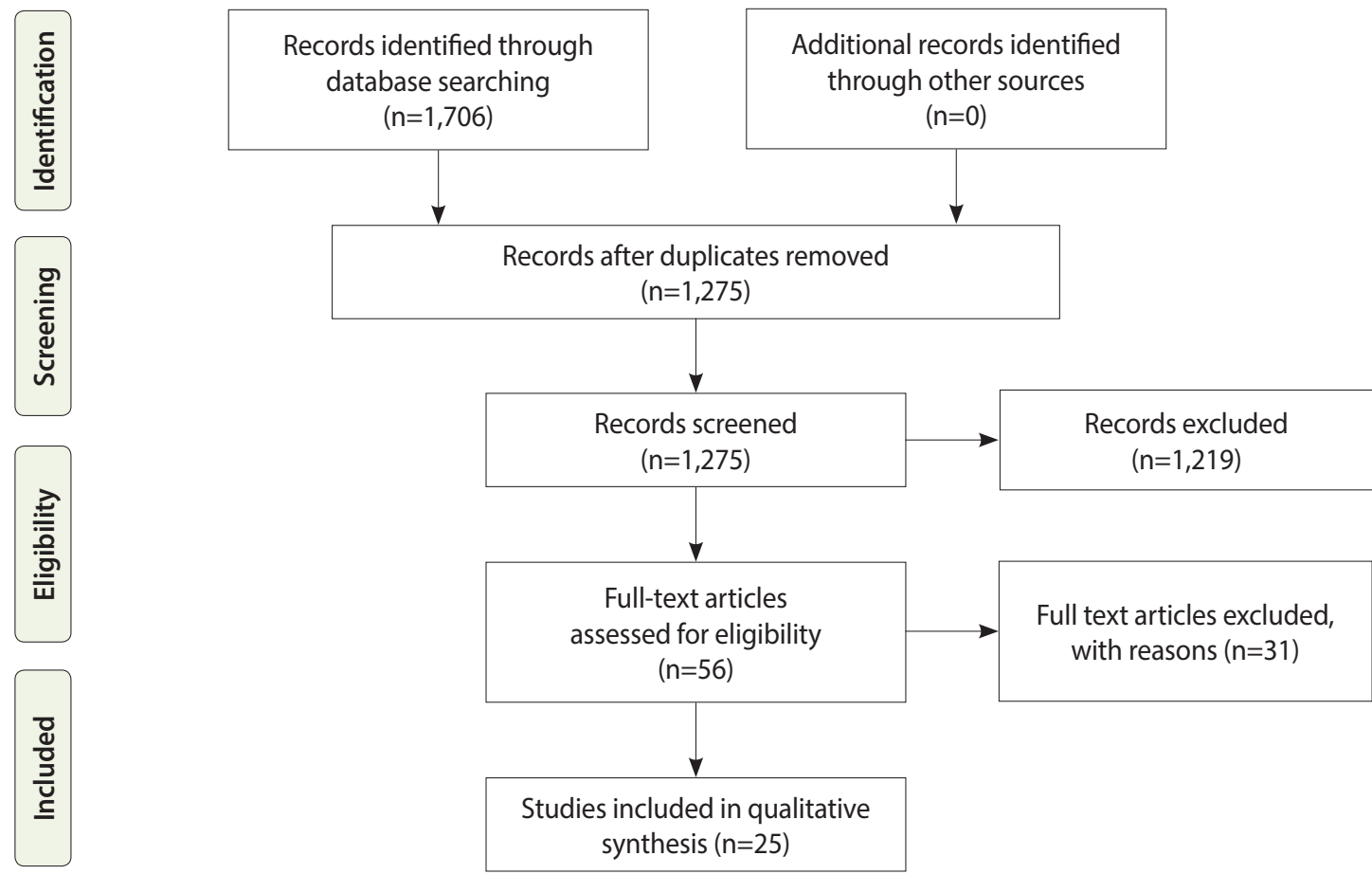

Figure 1. Flow chart for reviewing the literature and retrieval process. 


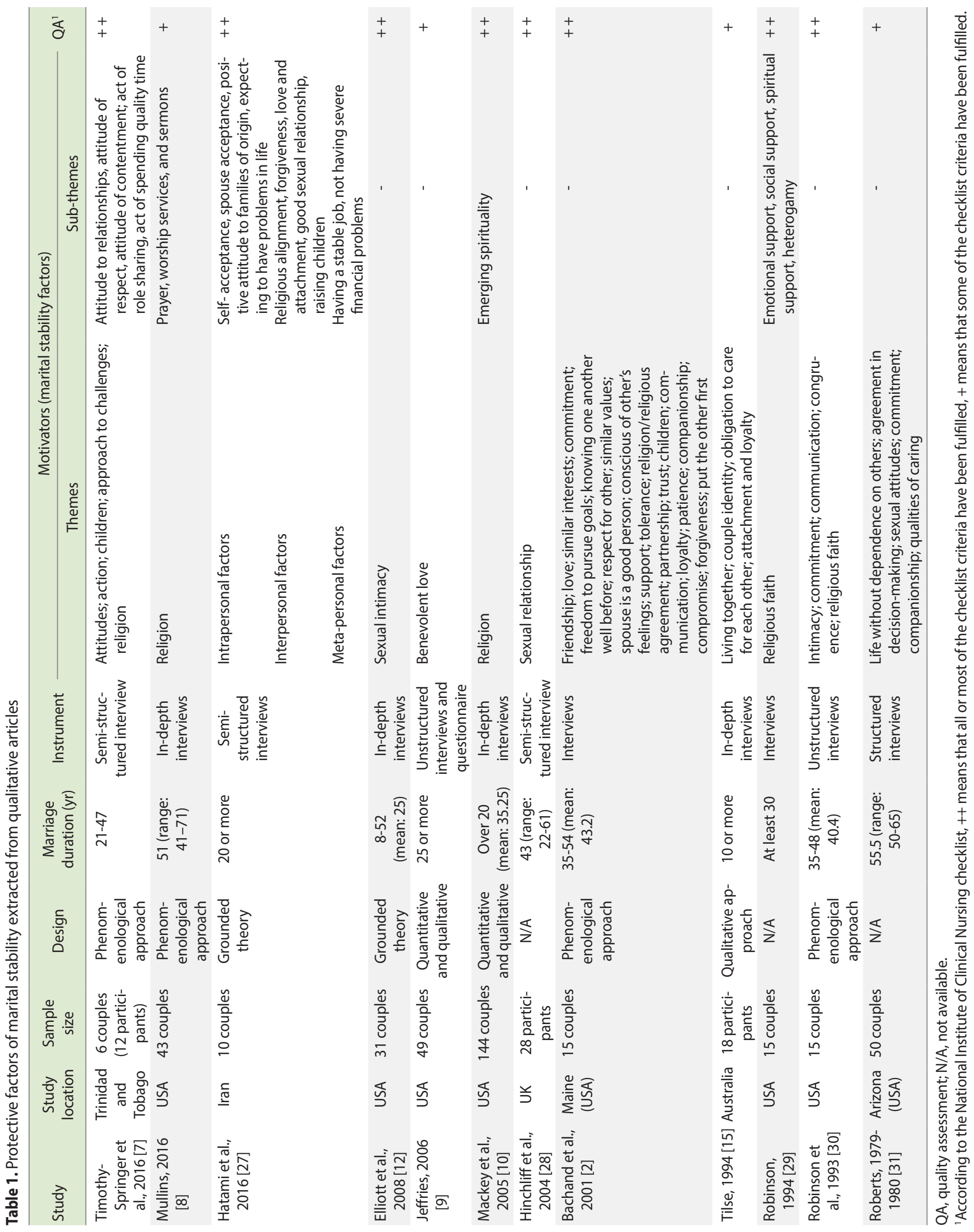




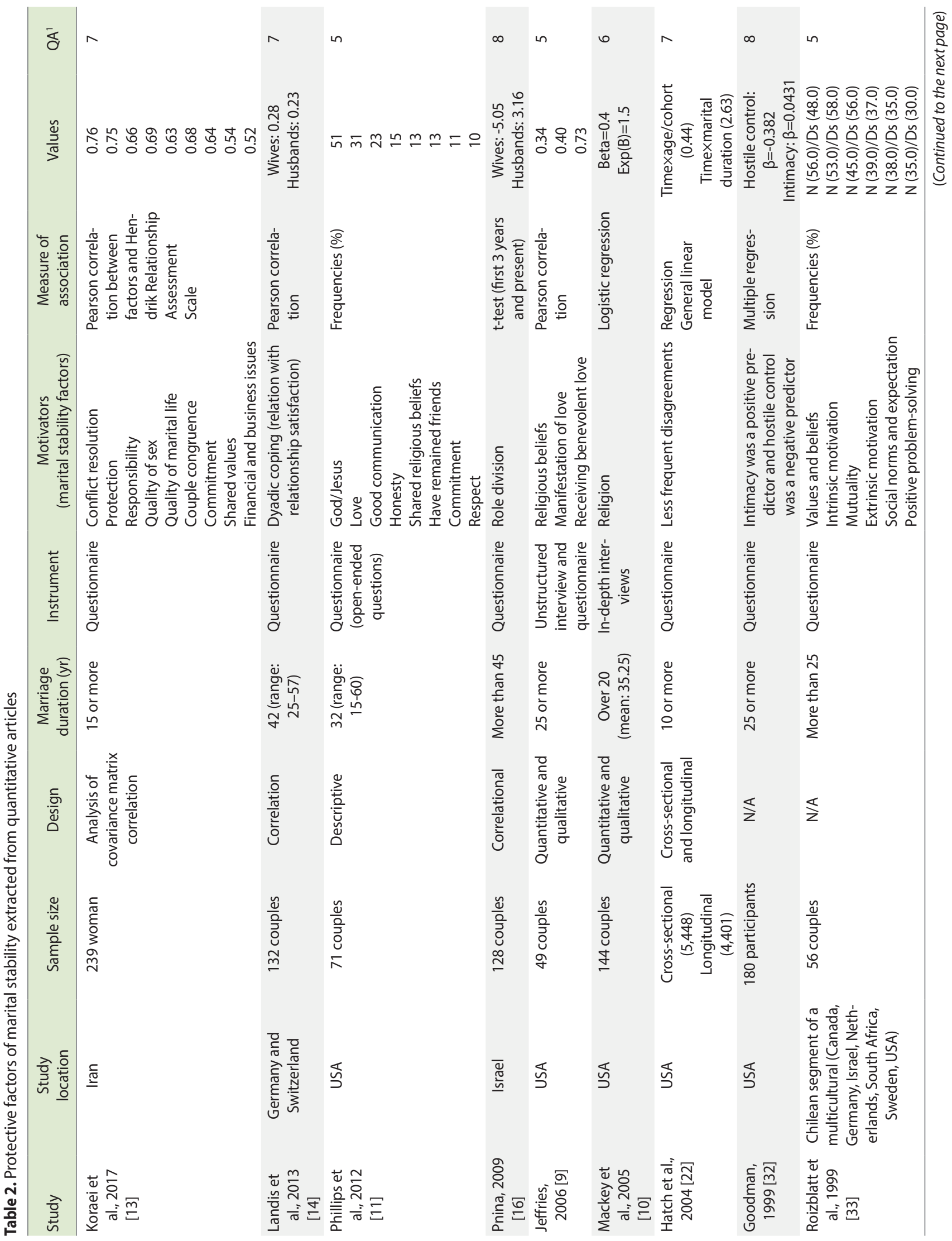




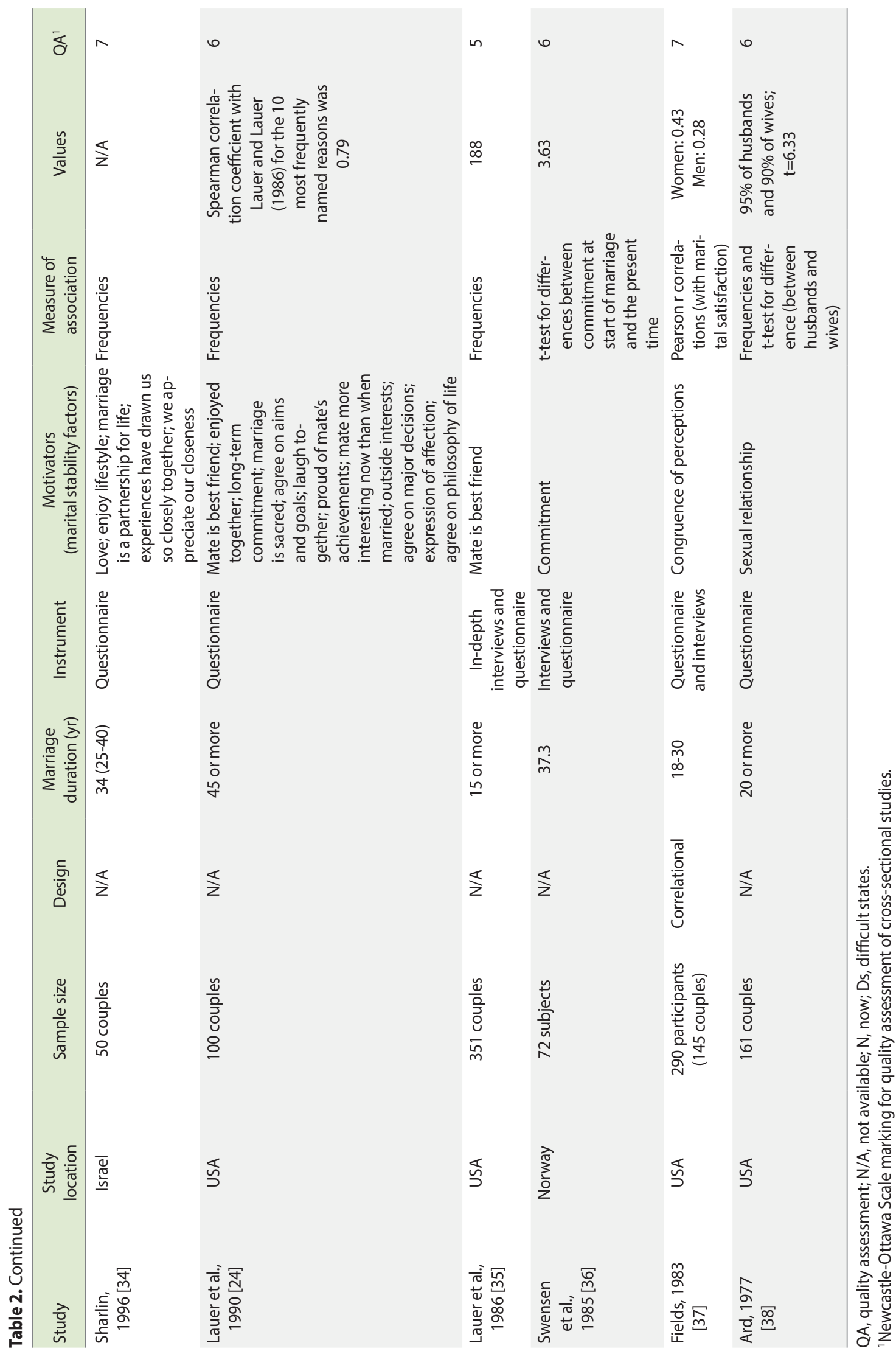


included study information and the participants' characteristics (e.g., gender, location, country), as well as motivations for longterm marriage. All disagreements were discussed with the third author if necessary.

\section{Quality assessment}

Qualitative studies were evaluated using the qualitative methodological checklist of the National Institute of Clinical Nursing (NICE). Generally, according to the NICE checklist, ++ means that all or most of the checklist criteria have been fulfilled, + means that some of the checklist criteria have been fulfilled, and - means that few or no checklist criteria have been fulfilled. Cross-sectional studies were examined using the Newcastle-Ottawa Scale for quality assessment, adapted for cross-sectional studies. This instrument is based on 3 domains, including the selection of study groups, comparability of groups, and description of exposure and outcome. All items except for the comparability domain have 1 star, and the maximum score based on stars for the comparability domain is 2 . The total number of earned stars corresponds to the total quality score for each study. A cut-off score of 6 or higher was considered as indicating high-quality studies. Two review authors completed the quality assessment independently. In cases of disagreement or items that remained unclear, the third author was consulted. As shown in the quality assessment sections of Tables 1 and 2, all qualitative and most quantitative articles were of appropriate quality, and only 4 papers were of borderline-acceptable quality.

\section{Ethics statement}

This study is a systematic review and does not deal with human participants.

\section{RESULTS}

The articles included in the review consisted of 12 qualitative and 13 quantitative articles, of which 2 were both qualitative and quantitative. Based on the findings from the articles, the extracted factors related to long-term marriage can be classified into several main categories or dimensions. As seen in Tables 1 and 2, protective factors in marital life can be divided into intrapersonal (or intra-dyadic) and interpersonal (extra-dyadic) factors. Prominent intrapersonal factors include religiosity and spirituality, commitment and loyalty, personality characteristics, capability to trust and empathize, patience, being supportive, forgiveness, and selfand other-acceptance. Prominent interpersonal factors consist of communication, sexual relationship, love and attachment, intimacy, religious agreement, mutual respect, role division, spending quality time, and approach to problem-solving and conflict resolution. Moreover, some aspects, such as the role of children and couples' financial issues, extend beyond the intrapersonal and interpersonal components.

As shown in Tables 1 and 2, in American countries, the most prominent aspects of couples' relationships linked to marital sta- bility consisted of religion, sexual relationship, commitment, intimacy, and congruence in values and beliefs. In Asian countries, the most prominent factors included communication, religion, children, conflict resolution, emotional issues and love, and in in European countries, the key factors included sexual relationship, commitment, relationship satisfaction, and support from one's mate.

A comprehensive list of the protective factors of marital stability extracted from qualitative and quantitative articles are shown in Tables 1 and 2.

\section{DISCUSSION}

The main finding of this study is that numerous components in many studies have been considered to be factors influencing longterm marriage stability. We divided these factors into interpersonal and intrapersonal or intra-dyadic and extra-dyadic factors. Interpersonal components refer to how behavioral interactions between members of couples are associated with relationship stability and quality, while intrapersonal components focus on how diversity in either psychopathology or personality characteristics relates to the functioning of couples' relationships [39,40].

According to the paradigm proposed by Karney \& Bradbury [21], 3 dimensions of couple's lives affect marital stability. First, enduring vulnerabilities are aspects such as psychological disorders that affect people's ability to interact efficiently in marital relationships. Second, stressful events include challenges such as unemployment in a couple's daily life, and third, adaptive processes include the manners of interaction such as approaches to conflict resolution that influence a couple's ability to successfully deal with daily stressors [41]. Therefore, we can implement the findings of the present study within this framework. Intrapersonal protective factors, such as commitment and loyalty, personality characteristics, capability to trust, and empathy can be considered as enduring vulnerabilities. Some components, such as social norms and expectations, play the role of stressful events. Next, many interpersonal factors are considered as adaptive processes, such as religious agreement and approaches to problem-solving, decision-making, and role division.

In most studies, the role of religion in long-term marriage has been highlighted. In moments of hardship, religion and spirituality are coping strategies that give couples commitment, capability to accept adversity, and a sense of family community and stability [42-46]. Similarly to the present study, numerous studies have emphasized the role of religion in marital stability and prevention of divorce [47-50]. Religious affiliation and attendance contribute to couples' well-being, and support and foster marital relationships [51,52]. Religious couples are happier, have higher life and marital satisfaction, and have marital boundaries that preserve them in conflict situations $[53,54]$. Furthermore, religion teaches that marriage is sacred and divorce is to be avoided, and marriage is a place to engage with other institutions, couples, and families that support family and couple life $[53,55]$. When people with re- 
ligious faith face difficulties, they enter into contact with God or another superior being, which gives them a sense of safety and control over the situation [56].

Commitment is defined as the desire to remain in the marriage even when confronted with confusion and difficulties [57]. Commitment theory states that couples with a powerful commitment to marriage consider marital problems to be solvable; because they believe that their paired unit can and must work to solve problems, they choose behavioral steps that improve marital relationships [58]. Therefore, we can conclude that committed couples develop an identity as a couple that gives them a sense of togetherness. Based on this, they consider themselves to be a pair with a common future, and make further efforts to preserve their identity as a couple.

Responsiveness to the positive emotions of one's partner plays a key role in fostering stable relationships [59]. When partners experience authentication of positive, rather than negative, emotions, the possibility of accepting incongruities among partners increases [60]. Carstensen et al. [61] found that in long-term marriages, husbands were more defensive than wives, whereas wives were more emotionally negative, and that partners in happy marriages engaged more in positive emotions than those in unhappy marriages. Therefore, we can infer that positive emotional engagement between partners in a couple leads to a happy marriage, and that happiness in marriage is a protective factor of marital stability.

Sexual satisfaction is necessary for marital stability and is correlated with general happiness, mental health, and successful social communications [62]. In contrast, Blümel et al. [63] concluded that a sexual relationship is not necessary for a couple's stability. This study also noted that good mutual understanding is a key element of a couple's sexual relationship and that sexual satisfaction arises in happy couples. Therefore, we can state that a sexual relationship is important, but the quality of communication is paramount.

There are different ways that partners in a couple can show affection to each other, but a healthy sexual relationship is considered to be a major signifier of marital well-being and a fundamental way that couples can show care and love to each other. Thus, it may be consider as a powerful symbol of a couple's relationship [12]. Sexual relations are an arena in which partners in a couple share love, intimacy, and deep feelings [64], creating a sense of unity and intimate belonging between couples, which leads to a diminution of individual boundaries and a strengthening of the couple's boundaries [65].

Conflict, which refers to disagreement or incompatibility between partners in a couple, is inevitable; however, experiencing high levels of stress in conflict can be destructive of marital satisfaction and stability [66]. Based on their attachment style, partners in a couple may resolve conflict (constructive engagement), intensify conflict (destructive engagement), or avoid conflict (conflict avoidance) [67]. Of these conflict management strategies, constructive engagement is considered to be a protective fac- tor in long-term relationships. Constructive engagement involves affirmative problem-solving approaches, which include mutual negotiation and conversation, cooperation with one's partner, and the willing commitment to openness, spousal support, and responsibility [66]. Additionally, a link of secure attachment between partners in a couple can create a sense of support and availability, which can generate a sense of care and empathy in times when it is needed [68].

Happy couples tend to perceive constraints such as shared property, friends, and children as sources of joy and evidence of investment [58]. When partners in the role of parents cooperate as a team to care for their children, this leads to a greater appreciation of the partner and a sense of care in the relationship [69,70]; therefore, raising children creates a sense of responsibility, teamwork, togetherness, and effectiveness between partners, which can promote a stable marriage.

Regarding gender differences in perspectives on the basic protective factors of marital stability, a number of the reviewed studies reported common components for men and women, while several other studies reported different findings. A point of common consensus is that gender for men and communication for women are crucial to marital stability, but there is no agreement on other components. It seems that future research should more focus on this age-old source of disputation through questionnaires and in-depth interviews of women and men to clarify their views on this issue.

This study has some important limitations that should be considered. First, the search was conducted only in the English and Persian languages. Access to articles in other languages would have increased the breadth of the study and its social and cultural richness. This limitation may have caused us to miss a number of valuable research studies. Second, we did not search a comprehensive set of databases, so there might have been important articles in uninvestigated databases that were not included in the current study. Another limitation is that some important data, such as couples' religion, number of children, age at first childbirth, economic status, age at the time of marriage, and status in terms of remarriage, were not investigated because few articles presented data on those factors. It is possible that information on these parameters would influence the interpretation of our findings. The final limitation is that because of inconsistency and heterogeneity in the statistical methods used in quantitative articles, it was not feasible to conduct a meta-analysis.

\section{CONCLUSION}

It should be noted that this study identified fundamental protective factors of marital stability in long-term marriage in different countries with diverse cultures. These protective factors are inherently associated with environmental and individual differences and the interactions between them. The originality of this systematic review lies in its strength-focused perspective on protective factors of marital stability and the fact that its results can 
be used to educate couples on ways to strengthen the foundations of the family and for counselors and clinicians to take a preventive perspective on many preventable cases of divorce.

\section{CONFLICT OF INTEREST}

The authors have no conflicts of interest to declare for this study.

\section{ACKNOWLEDGEMENTS}

None.

\section{AUTHOR CONTRIBUTIONS}

Conceptualization: RK, MB. Data curation: RK, MB, AMA. Formal analysis: RK, AMA. Funding acquisition: None. Methodology: RK, MB, AMA. Project administration: RK, AMA. Visualization: RK, MB, AMA. Writing - original draft: RK, MB. Writing - review \& editing: $\mathrm{RK}, \mathrm{MB}, \mathrm{AMA}$.

\section{ORCID}

Reza Karimi: https://orcid.org/0000-0001-9274-4565; Maryam Bakhtiyari: https://orcid.org/0000-0002-5106-9775; Abbas Masjedi Arani: https://orcid.org/0000-0001-5521-0257

\section{REFERENCES}

1. Benson JJ, Coleman M. Older adults developing a preference for living apart together. J Marriage Fam 2016;78:797-812.

2. Bachand LL, Caron SL. Ties that bind: a qualitative study of happy long-term marriages. Contemp Fam Ther 2001;23:105-121.

3. Cohen O, Geron Y, Farchi A. A typology of marital quality of enduring marriages in Israel. J Fam Issues 2010;31:727-747.

4. Lawrence E, Nylen K, Cobb RJ. Prenatal expectations and marital satisfaction over the transition to parenthood. J Fam Psychol 2007; 21:155-164.

5. Hollist CS, Miller RB. Perceptions of attachment style and marital quality in midlife marriage. Fam Relat 2005;54:46-57.

6. Nimtz MA. Satisfaction and contributing factors in satisfying long-term marriage: a phenomenological study [dissertation]. Lynchburg: Liberty University; 2011.

7. Timothy-Springer R, Johnson EJ. Qualitative study on the experiences of married couples. J Hum Behav Soc Environ 2016;28: 889-902.

8. Mullins D. The effects of religion on enduring marriages. Soc Sci 2016;5:24.

9. Jeffries V. Religiosity, benevolent love, and long-lasting marriages. Humboldt J Soc Relat 2006;30:77-106.

10. Mackey RA, O'Brien BA. The significance of religion in lasting marriages. J Relig Spiritual Aging 2005;8:35-63.

11. Phillips TM, Wilmoth JD, Marks LD. Challenges and conflicts... strengths and supports: a study of enduring African American marriages. J Black Stud 2012;43:936-952.

12. Elliott S, Umberson D. The performance of desire: gender and sexual negotiation in long-term marriages. J Marriage Fam 2008; 70:391-406.

13. Koraei A, Mehr RK, Sodani M, Aslani K. Identification of the factors contributing to satisfying stable marriages in women. J Fam Couns Psychother 2017;6:129-164 (Persian).

14. Landis M, Peter-Wight M, Martin M, Bodenmann G. Dyadic coping and marital satisfaction of older spouses in long-term marriage. GeroPsych (Bern) 2013;26:39-47.

15. Tilse C. Long term marriage and long term care "we thought we'd be together till we died”. Aust J Ageing 1994;13:172-174.

16. Pnina R. The differences in role division between partners in longterm marriages and their well-being. J Fam Soc Work 2009;12: 44-55.

17. Rauer A, Williams L, Jensen J. Finer distinctions: variability in satisfied older couples' problem-solving behaviors. Fam Process 2017;56:501-517.

18. Birditt KS, Wan WH, Orbuch TL, Antonucci TC. The development of marital tension: implications for divorce among married couples. Dev Psychol 2017;53:1995-2006.

19. Rauer A, Volling B. More than one way to be happy: a typology of marital happiness. Fam Process 2013;52:519-534.

20. Umberson D, Williams K, Powers DA, Liu H, Needham B. You make me sick: marital quality and health over the life course. J Health Soc Behav 2006;47:1-16.

21. Karney BR, Bradbury TN. The longitudinal course of marital quality and stability: a review of theory, method, and research. Psychol Bull 1995;118:3-34.

22. Hatch LR, Bulcroft K. Does long-term marriage bring less frequent disagreements? Five explanatory frameworks. J Fam Issues 2004;25:465-495.

23. Gottman JM, Notarius CI. Decade review: observing marital interaction. J Marriage Fam 2000;62:927-947.

24. Lauer RH, Lauer JC, Kerr ST. The long-term marriage: perceptions of stability and satisfaction. Int J Aging Hum Dev 1990;31: 189-195.

25. Acitelli LK, Antonucci TC. Gender differences in the link between marital support and satisfaction in older couples. J Pers Soc Psychol 1994;67:688-698.

26. Rhyne D. Bases of marital satisfaction among men and women. J Marriage Fam 1981;43:941-955.

27. Hatami VA, Esmaeily M, Farahbakhsh K, Borjali A. Long term satisfied marriage model: a grounded theory study. J Fam Couns Psychother 2016;6:120-149 (Persian).

28. Hinchliff S, Gott M. Intimacy, commitment, and adaptation: sexual relationships within long-term marriages. J Soc Pers Relat 2004; 21:595-609.

29. Robinson LC. Religious orientation in enduring marriage: an exploratory study. Rev Relig Res 1994;35:207-218.

30. Robinson LC, Blanton PW. Marital strengths in enduring marriages. Fam Relat 1993;42:38-45.

31. Roberts WL. Significant elements in the relationship of long-mar- 
ried couples. Int J Aging Hum Dev 1979-1980;10:265-271.

32. Goodman C. Intimacy and autonomy in long term marriag. J Gerontol Soc Work 1999;32:83-97.

33. Roizblatt A, Kaslow F, Rivera S, Fuchs T, Conejero C, Zacharias A. Long lasting marriages in Chile. Contemp Fam Ther 1999;21:113129.

34. Sharlin SA. Long-term successful marriages in Israel. Contemp Fam Ther 1996;18:225-242.

35. Lauer RH, Lauer JC. Factors in long-term marriages. J Fam Issues 1986;7(4):382-390.

36. Swensen CH, Trahaug G. Commitment and the long-term marriage relationship. J Marriage Fam 1985;47:939-945.

37. Fields NS. Satisfaction in long-term marriages. Soc Work 1983; 28:37-41.

38. Ard BN Jr. Sex in lasting marriages: a longitudinal study. J Sex Res 1977;13:274-285.

39. Donnellan MB, Assad KK, Robins RW, Conger RD. Do negative interactions mediate the effects of negative emotionality, communal positive emotionality, and constraint on relationship satisfaction? J Soc Pers Relat 2007;24(4):557-573.

40. Caughlin JP, Huston TL, Houts RM. How does personality matter in marriage? An examination of trait anxiety, interpersonal negativity, and marital satisfaction. J Pers Soc Psychol 2000;78:326336.

41. Boerner K, Jopp DS, Carr D, Sosinsky L, Kim SK. "His" and "her" marriage? The role of positive and negative marital characteristics in global marital satisfaction among older adults. J Gerontol B Psychol Sci Soc Sci 2011;69:579-589.

42. Cutrona CE, Russell DW, Burzette RG, Wesner KA, Bryant CM. Predicting relationship stability among midlife African American couples. J Consult Clin Psychol 2011;79:814-825.

43. Wilcox WB, Wolfinger NH. Then comes marriage? Religion, race, and marriage in urban America. Soc Sci Res 2007;36:569-589.

44. Shorter-Gooden K. Multiple resistance strategies: how African American women cope with racism and sexism. J Black Psychol 2004;30:406-425.

45. Mattis JS. Religion and spirituality in the meaning-making and coping experiences of African American women: a qualitative analysis. Psychol Women Q 2002;26:309-321.

46. Brodsky AE. The role of religion in the lives of resilient, urban, African American, single mothers. J Community Psychol 2000; 28:199-219.

47. Li S, Kubzansky LD, VanderWeele TJ. Religious service attendance, divorce, and remarriage among U.S. nurses in mid and late life. PLoS One 2018;13:e0207778.

48. McClendon D. Religion, marriage markets, and assortative mating in the United States. J Marriage Fam 2016;78:1399-1421.

49. Uecker J. Religion and early marriage in the United States: evidence from the Add Health Study. J Sci Study Relig 2014;53:392415.

50. Brown SM, Porter J. The effects of religion on remarriage among American women: evidence from the National Survey of Family Growth. J Divorce Remarriage 2013;54:142-162.
51. Brown SL, Lin IF. The gray divorce revolution: rising divorce among middle-aged and older adults, 1990-2010. J Gerontol B Psychol Sci Soc Sci 2012;67:731-741.

52. Amato PR. Research on divorce: continuing trends and new developments. J Marriage Fam 2010;72:650-666.

53. Tuttle JD, Davis SN. Religion, infidelity, and divorce: reexamining the effect of religious behavior on divorce among long-married couples. J Divorce Remarriage 2015;56:475-489.

54. Vaaler ML, Ellison CG, Powers DA. Religious influences on the risk of marital dissolution. J Marriage Fam 2009;71:917-934.

55. Simonič B, Klobučar NR. Experiencing positive religious coping in the process of divorce: a qualitative study. J Relig Health 2017; 56:1644-1654.

56. Webb AP, Ellison CG, McFarland MJ, Lee JW, Morton K, Walters J. Divorce, religious coping, and depressive symptoms in a conservative protestant religious group. Fam Relat 2010;59:544-557.

57. Schoebi D, Karney BR, Bradbury TN. Stability and change in the first 10 years of marriage: does commitment confer benefits beyond the effects of satisfaction? J Pers Soc Psychol 2012;102:729742.

58. Stanley SM, Rhoades GK, Whitton SW. Commitment: functions, formation, and the securing of romantic attachment. J Fam Theory Rev 2010;2:243-257.

59. Petrican R, Rosenbaum RS, Grady C. Neural activity patterns evoked by a spouse's incongruent emotional reactions when recalling marriage-relevant experiences. Hum Brain Mapp 2015; 36:4164-4183.

60. Petrican R, Burris CT, Bielak T, Schimmack U, Moscovitch M. For my eyes only: gaze control, enmeshment, and relationship quality. J Pers Soc Psychol 2011;100:1111-1123.

61. Carstensen LL, Gottman JM, Levenson RW. Emotional behavior in long-term marriage. Psychol Aging 1995;10:140-149.

62. Nourani S, Jonaidy E, Shakeri MT, Mokhber N. Sexual satisfaction in fertile and infertile women attending state clinics in Mashad. J Reprod Infertil 2010;10:269-277 (Persian).

63. Blümel JE, Castelo-Branco C, Cancelo MJ, Romero H, Aprikian D, Sarrá S. Impairment of sexual activity in middle-aged women in Chile. Menopause 2004;11:78-81.

64. Schoenfeld EA, Bredow CA, Huston TL. Do men and women show love differently in marriage? Pers Soc Psychol Bull 2012;38: 1396-1409.

65. Ganong K, Larson E. Intimacy and belonging: the association between sexual activity and depression among older adults. Soc Ment Health 2011;1:153-172.

66. Feeney JA, Karantzas GC. Couple conflict: insights from an attachment perspective. Curr Opin Psychol 2017;13:60-64.

67. Straus MA, Gozjolko KL. "Intimate terrorism" and gender differences in injury of dating partners by male and female university students. J Fam Violence 2014;29:51-65.

68. Shaver PR, Mikulincer M, Cassidy J. Attachment, caregiving in couple relationships, and prosocial behavior in the wider world. Curr Opin Psychol 2019;25:16-20.

69. Lashewicz B, Boettcher N, Lo A, Shipton L, Parrott B. Fathers rais- 
ing children with autism spectrum disorder: stories of marital stability as key to parenting success. Issues Ment Health Nurs 2018; 39:786-794.
70. Hock RM, Timm TM, Ramisch JL. Parenting children with autism spectrum disorders: a crucible for couple relationships. Child Fam Soc Work 2012;17:406-415. 